\title{
Comparison of intra- vs extradimensional transfer of matching by rhesus monkeys 1,2
}

WILLIAM J. JACKSON, ${ }^{3}$ University of
South Florida, Tampa, Fla. 33620, and G.
VERNON PEGRAM, 6571st Aeromedical
Research Laboratory, Holloman AFB, N. Mex. 88330

Monkeys were trained to match red, green, and blue disks in a two-choice matching-to-sample paradigm. Once the monkeys' performance was asymptotic, a novel yellow disk was introduced into the paradigm, with the monkeys showing complete and immediate transfer of matching. However, when a novel triangular form was intr. duced into the paradigm, the same mor.ievs continued to respond to the familiar .ured disks.

Cumming \& Berryman (1961) trained pigeons to match red, blue, and green disks to a high level of performan:e. They silen replaced the blue disk with a yeilow one and tested for intradime'isional transfer. The birds reverted to a position habit on those trials in which the $t$ ivel yellow hue served as the sample stimulus, but maintained their previous ability to match the green and the red stir uli. This paper describes the results of a similar experiment using monkrys as Ss. In addition to the intradime ssional transfer problem used by Cumming 'nc' Berryman, the monkeys were also :xposed to an extradimensional transfer problem in which the novel stimulus was a white triangle.

Four rhesus monkeys (Macaca mulatta) served as $S s$ for the intradimensional transfer, and the same animals served as Ss for the extradimensional transfer. The monkeys weighed $2.9-3.1 \mathrm{~kg}$ at the beginning of testing and dental eruptions indicated that the animals were approximately $32-36$ months of age. All monkeys had previous experience in delayed matching of red, green, and blue disks that had been presented on the same apparatus used in this experiment. The monkeys were housed individually for the duration of the experiment and were transported to and from the test area by means of collar and leash. Furthermore, the animals were chair adapted by extensive handling prior to testing. All

Fig. 1. Individual stimulus analyses of the monkeys' performance during the final session of stabilization, the intradimensional transfer sessiun, and the two sessions of extradimensional transfer. animals were fed fruit and Purina Monkey Chow after each test session in sufficien quantity to allow approximately $.1 \mathrm{~kg}$ per month increase in body weight. APPARATUS

The matching tasks were presented on a performance panel which consisted of three transparent push reys and a food hopper. Stimuli were presented on the screens of in-line-digital-display units (IDDs), which were located behind the push keys. The form of the colored stimuli was a 1-in.-diam disk. The key used to present the sample or standard stimulus (ST) was centered 1 in. above the two keys used to present the comparison stimuli (CO). The food hopper was centered $1 \frac{11}{2}$ in. helow the two CO keys. Testing was conducted while the animals were seated in a primate restraint chair, which was located within a large chamber having very good sound attenuating characteristics. Diffuse general illumination was provided by a ceiling light.

\section{PROCEDURE}

Immediately prior to the beginning of this experiment, the Ss had been
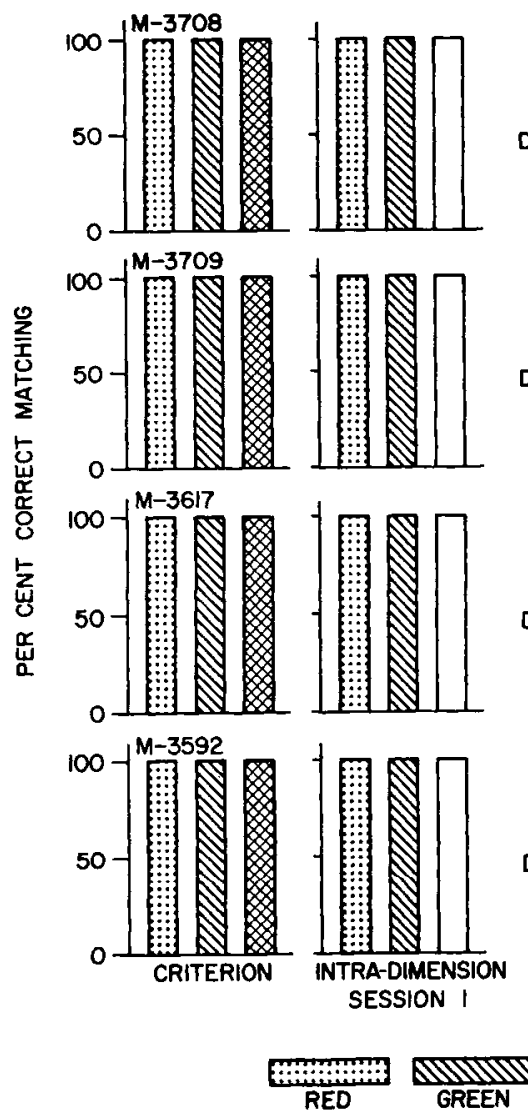

performing a delayed matching task using red, green, and blue disks as stimuli. In the present procedure, the monkeys were required to match the same stimuli in a simultaneously presented paradigm until they attained the criterion of $95 \%$ correct matching within a day's testing. Daily sessions consisted of 120 trials, each of which began by presenting ST alone, with ST remaining lighted until the monkey responded. A ST response resulted in the presentation of the two $\mathrm{CO}$, with ST remaining lighted. After the first ST response, additional responses to ST did not change the stimulus configuration for the remainder of that particular trial. Responses to the matching $\mathrm{CO}$ were reinforced by a 300-mg banana-flavored Ciba Nutrient pellet. A response to the odd CO produced only the intertrial interval, which was always $25 \mathrm{sec}$. The order of the trials during each session was randomly varied among six different sequences. In all of these sequences, each color appeared an equal number of times on each stimulus panel.

During the session following the attainment of criterion, the animals were given an intradimensional transfer session in which the blue stimulus was replaced by a yellow stimulus, wherever blue might have appeared. The remaining two colors were unchanged.
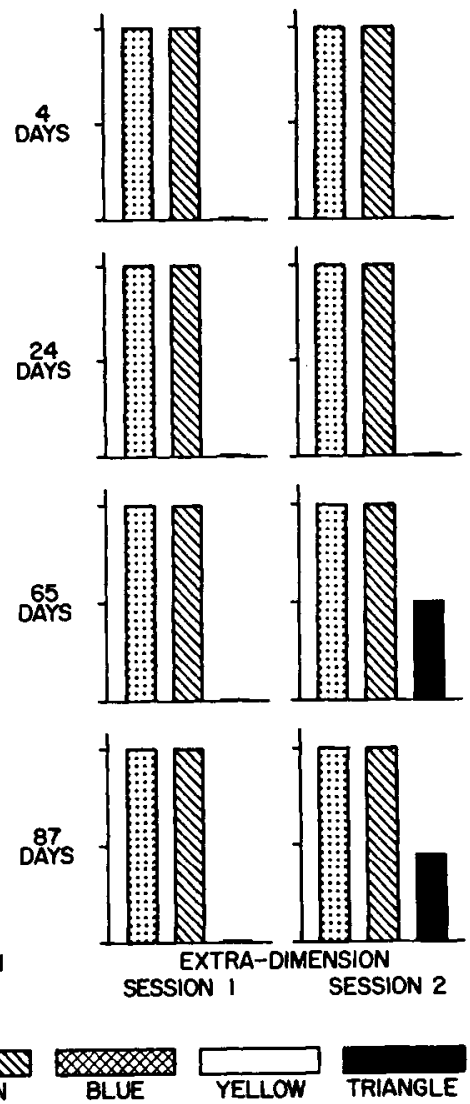
The extradimensional transfer session was administered some time after the intradimensional transfer. This time period varied from 4 days to 87 days for the four animals. The procedure for the extradimensional transfer was as follows: The monkeys were again stabilized on the red, green, and blue simultaneous matching paradigm until they attained a criterion of three consecutive sessions of $95 \%$ or better matching performance. The length of time between the intra- and extradimensional tasks did not seem to affect the nuriber of days required to reach criterion, since the animal with the longest time interval required three sessions to reach criterion, as did the animal with the shortest interval. During the session following the attainment of criterion, the blue stimulus was again replaced, this time with a white triangle having $3 / 4$-in. sides.

\section{RESULTS AND DISCUSSION}

As Fig. 1 shows, all monkeys immediately transferred matching to the yellow stimulus, but during the first session of extradimensional transfer, the monkeys responded to the colored stimulus whenever the triangle appeared as a $\mathrm{CO}$. Two monkeys began to match the triangle during the second session of extradimensional transfer, while neither of the other monkeys responded to the triangle even once during the two sessions of extradimensional transfer. Although we can offer no immediate explanation, it is of interest to note that the monkeys that began to respond to the triangle during the second session had a longer time period between testing on the intradimensional and extradimensional transfer tasks. During both extra- and intradimensional transfer,

\section{The effects of stimuli associated with shock onset}

\section{or termination on restraint-induced gastric lesions ${ }^{1}$}

\author{
DOUGLAS D. FIFE, University of South \\ Dakota, Vermillion, S. Dak. 57069
}

Rats under physical restraint were presented a CS that was previously paired with either shock onset or electric shock termination, or at random intervals before and after shock onset (control). The group exposed to the CS previously paired with shock onset had significantly more gastric lesions than did the other two groups, which did not differ. These results support the findings of studies which measured an all monkeys continued to match correctly in those trials in which the red and the green stimuli were ST.

These findings contrast with Cumming and Berryman's observations upon transfer of matching by pigeons. In an almost identical intradimensional transfer situation, the pigeons reverted to a position habit on trials in which the novel yellow stimulus was the ST, and this performance was interpreted as indicating that previous training had not resulted in the formation of a matching concept. However, the monkeys apparently did form at least a rudimentary matching concept, since matching was transferred $100 \%$ to the novel intradimensional stimulus. Nevertheless, the failure of the same monkeys to transfer matching to the novel extradimensional stimulus suggests that monkeys may not transfer their matching performance across certain stimulus dimensions.

\section{REFERENCES}

CUMMING, W. W., \& BERRYMAN, R. Some data on matching behavior in the pigeon. Journal of the Experimental Analysis of Behavior, 1961, 4, 281-284. NOTES

1. This research was supported by U.S. Public Health Service Research Grant MH 16635-01 from the National Institute of Mental Health and by various funds from the 6571 st Aeromedical Research Laboratory, Holloman AFB, N. Mex.

2. Animals used in this study were handled in accordance with the "Guide for Laboratory Animal Facilities and Care" prepared by the National Academy of Sciences, National Research Council, and in accordance with the Secretary of Agriculture Standards in "Laboratory Animal Welfare."

3. Requests for reprints should be sent to William J. Jackson, 6571st Aeromedical Research Laboratory, Holloman AFB, N. Mex. function as a positive reinforcer. The differential reinforcing effects of a CS once paired with shock onset as opposed to a CS paired with shock termination have been demonstrated in studies of barpressing (Mowrer \& Aiken, 1954), activity (Davitz, 1955), and stimulus preference (Goodson \& Brownstein, 1955).

The frequency of gastric lesions has been employed as a dependent variable in studies involving conflict (Sawrey \& Weisz, 1956), Sidman avoidance conditioning (Brady, Porter, Conrad, \& Mason, 1958), and physical restraint (Rossi, Bonfils, Lieffogh, \& Lambling, 1956). Sawrey \& Sawrey (1964) performed an experiment that combined the presentation of a CS having negatively reinforcing properties with physical restraint, and used frequency of gastric lesions as the dependent variable. These investigators found a higher frequency of gastric lesions when the CS paired with onset of electric shock was later presented to rats under physical restraint than when a backwardconditioned CS (control) was presented during restraint. Sawrey \& Sawrey (1964) suggested that since restraint-induced gastric lesions occur in response to changes in autonomic functioning, then frequency of lesions may be an indirect measure of autonomic conditioning in response to the presentation of a CS with negatively reinforcing properties. It was further suggested that frequency of gastric lesions may be a more direct measure of the effects of the negative reinforcing properties of this CS than the measurements used in an instrumental conditioning situation.

The present study was designed to compare the effects of the CS associated with shock onset and the effects of a CS associated with shock termination on restraint-induced gastric lesions. If it is correct that frequency of lesions is a good measure of the strength of the negative reinforcing properties of a CS, then there should be a difference in the frequency of lesions between Ss presented this type of CS and Ss presented a CS previously paired with shock termination. This difference, if found, would parallel the findings of studies that reported a behavioral difference in the presence of these two CSs. wects of a CS associated with shock onset were different from the effects of a CS previously paired with shock termination.

Estes \& Skinner (1941) demonstrated that a CS that had been previously paired with shock onset would function as a negative reinforcer. Mowrer (1956) proposed that a CS presented after shock onset, and immediately prior to the termination of electric shock, would have a different effect on behavior and would

\section{SUBJECTS}

Thirty-six male Long-Evans rats, $70-100$ days of age at the beginning of the experiment, were assigned randomly to three groups of equal size. All Ss were deprived of food and water for $23 \mathrm{~h}$ prior to conditioning and were maintained on a 23-h deprivation schedule throughout conditioning. Upon completion of conditioning trials, Ss were allowed food 